\title{
The Association between Autism Spectrum Disorder and Pre- and Postnatal Antibiotic Exposure in Childhood-A Systematic Review with Meta-Analysis
}

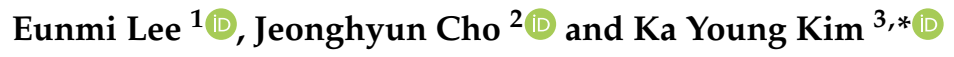 \\ 1 Department of Nursing, Research Institute for Basic Sciences, Hoseo University, Asan 31499, Korea; \\ sweetbear2@hanmail.net \\ 2 Department of Nursing, College of Medicine, Inje University, Busan 47392, Korea; jhcho@inje.ac.kr \\ 3 Department of Nursing, College of Nursing, Gachon University, Incheon 21936, Korea \\ * Correspondence: kykim@gachon.ac.kr
}

Received: 8 October 2019; Accepted: 18 October 2019; Published: 22 October 2019

\begin{abstract}
Autism spectrum disorder (ASD) is a developmental disorder that begins in early childhood and has been associated with several environmental and genetic factors. We aimed to conduct two-side meta-analyses to determine the association between ASD and pre- and postnatal antibiotic exposure in childhood. We searched PubMed, Embase, Web of Science, and Cochrane Library for articles published up to February 2019. We evaluated observational studies that assessed the association between ASD and antibiotic exposure. Of 1459 articles, nine studies were used in the meta-analysis. We found that early antibiotic exposure, including pre- and postnatal, significantly increased the ASD risk in children. Furthermore, early antibiotic exposure, including pre- and postnatal, was significantly increased in children with ASD. Specifically, prenatal antibiotic exposure was significantly increased in children with ASD; however, postnatal antibiotic exposure was not. Our results indicate an association between ASD and early antibiotic exposure; specifically, that prenatal antibiotic exposure is an important risk factor of ASD in children.
\end{abstract}

Keywords: antibiotic exposure; autism spectrum disorder (ASD); childhood; meta-analysis; systematic review

\section{Introduction}

Autism spectrum disorder (ASD) is a neurodevelopmental disorder characterized by communication and interaction difficulties as well as repeated and stereotyped behaviors and interests [1]. Approximately 66 million individuals worldwide have ASD, and it has been reported to begin early in life [2-4].

Although the exact cause of ASD is unknown, genetic factors are key contributors. Further, various environmental factors are involved and are considered an important aspect of the increased prevalence of ASD [5-7]. Rapid industrialization and the consequent environmental pollution have also increased the risk of exposure to toxic substances via various pathways. Since ASD occurs early in life, studies have reported that toxic exposure, such as mercury poisoning in the prenatal or childhood period, could cause ASD [8]. Therefore, infant mercury poisoning caused by seafood consumption by the mother, pediatric vaccination, and prenatal use of antibiotics has been suggested to cause ASD [9]. Moreover, studies have reported that pre- [10-12] and postnatal exposure to antibiotics and acetaminophen increases the ASD risk [13-16]. 
Although antibiotics are essential for treating some diseases, antibiotic exposure has been associated with various diseases. Antibiotic use can cause abnormal changes in the human microbiome. Studies have suggested that when the altered microbiome is passed onto the fetus, it increases the risk of colitis and ASD by impeding neurological development [13,17-19]. Further, antibiotic exposure has been reported to be weakly associated with the risk for ASD [10]; however, this association cannot be clearly established given the difficulty of measuring fetal antibiotic exposure. Studies have also reported that postnatal antibiotic exposure is associated with ASD; specifically, postnatal use of acetaminophen and antibiotics, as well as ear infection, were reported to increase the risk for ASD [16].

This indicates that despite continued studies on the association between ASD and antibiotics, a definitive conclusion is yet to be reached. Particularly, the lack of consensus on pre- and postnatal antibiotic exposure has hindered efforts toward determining this relationship. Therefore, we aimed to conduct two-side meta-analyses to clearly determine the relationship between ASD and antibiotic use as well as present foundational data for preventive and management strategies for lowering the ASD risk.

\section{Methods}

\subsection{Search Strategy and Selection Criteria}

This meta-analysis was performed in accordance with the PRISMA guidelines [20] and was approved by the institutional review board of Gachon University (1044396-201909-HR-160-01). We searched PubMed, Embase, Web of Science, and Cochrane Library databases for all relevant studies written in English and published before February 2019. The search terms used were (antibiotic* OR antimicrob*) and (autism* OR ASD OR kanner syndrome OR PDD OR pervasive developmental disorder). For meta-analysis, we included studies that reported the association between ASD and pre- or postnatal antibiotic exposure in childhood and excluded studies that did not report the antibiotic exposure level as well as the ASD and control group. We included observational studies, including case-control, cross-sectional, and cohort studies and excluded commentary, editorial, and review articles.

\subsection{Data Extraction and Analysis}

All authors independently screened and selected relevant data, and any disagreements were resolved by discussion. We extracted relevant data, including first author, publication year, study design, country, sample size, age of participants, and related outcomes. Moreover, to assess the association between ASD and pre- or postnatal antibiotic exposure in childhood, we extracted all measurement data including prevalence data of patients with ASD and controls group as well as the number and amount of pre- and postnatal antibiotic exposure. The risk estimates of ASD in antibiotic exposure and the standardized mean difference (SMD) of antibiotic exposure in ASD were analyzed via meta-analysis using the Comprehensive Meta-Analysis software version 3 (Biostat Inc., Englewood, $\mathrm{NJ}$, USA). We assessed the heterogeneity using the $\mathrm{Q}$ statistic and $I^{2}$ method, while the random-effects model was applied in all analyses to address heterogeneity. Subgroup analyses were performed based on group differences in prenatal and postnatal exposure. Publication bias was assessed using funnel plots and Egger's intercept. $p<0.05$ indicated a significant difference. Furthermore, for quality assessment, we used the Newcastle-Ottawa Scale (NOS) to assess the methodological quality of the nine included studies [21,22]. The NOS is a representative tool developed for meta-analysis of non-randomized comparative studies, including case-control, cross-sectional, and cohort studies. It comprises an adjustment item with the selection of study groups, comparability of the groups, and determination of either the exposure or outcome of interest to evaluate the quality of articles included in the meta-analyses. 


\section{Results}

\subsection{Characteristics of the Studies}

We initially identified 1877 studies (Figure 1), and after the elimination of duplicates using the Endnote reference database, 1459 studies remained. We excluded 1348 articles based on the titles and 60 articles based on the abstract, and thus were left with 51 articles that were eligible for full-text screening. After close review, 42 publications were excluded because of lack of usable data and failure to meet the inclusion criteria. Finally, a total of nine articles were identified and included in the meta-analysis. Table 1 shows the characteristics of the nine selected studies, which were published between 2007 and 2019. Moreover, regarding study design, there were 5, 1, and 3 case-control, cross-sectional, and cohort studies, respectively. The subjects ranged from 27 to 949,821 . All studies were performed in the USA, Denmark, Italy, Lebanon, Canada, and Sweden. The age of the subjects ranged from birth to 18 years. The outcomes of the nine studies were only described as related content regarding ASD and antibiotic usage. In addition, the quality scores ranged from 5 to 8 .

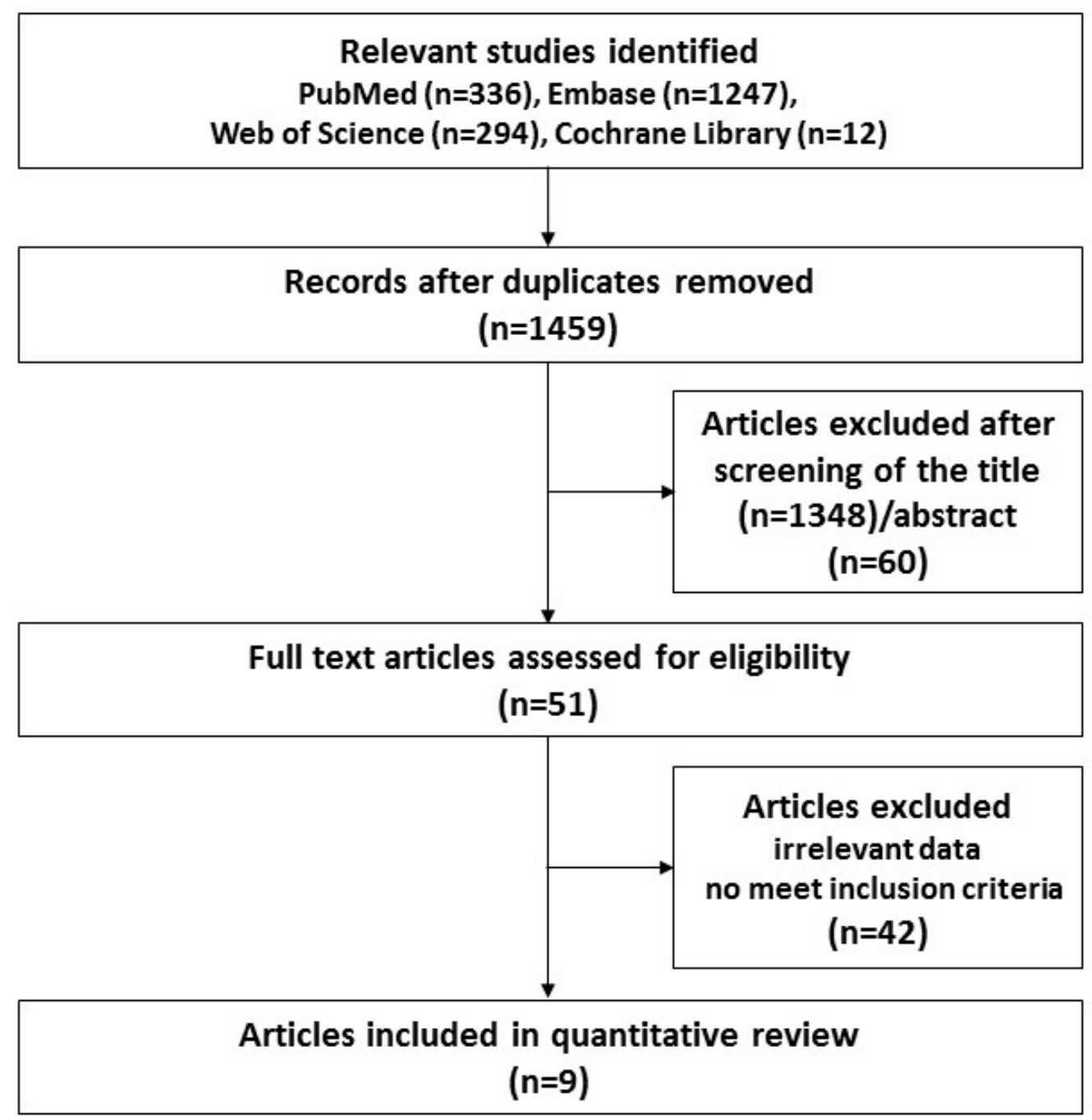

Figure 1. Flow chart for the study selection process. 
Table 1. Characteristics of the 9 included studies on the association between antibiotic exposure and autism spectrum disorder (ASD) in children.

\begin{tabular}{|c|c|c|c|c|c|c|}
\hline Study & Study Type & Participants & Location & Age & Outcome & Quality * \\
\hline Adams et al., 2007 [15] & Case-control & 27 & USA & $3-8$ years & $\begin{array}{l}\text { Children with autism showed higher oral antibiotic usage in } \\
\text { various time periods. }\end{array}$ & 5 \\
\hline Atladóttir et al., 2012 [12] & Cohort & 976 & Denmark & 8-14 years & $\begin{array}{l}\text { The use of various antibiotics showed an increased risk of } \\
\text { ASD/infantile autism. }\end{array}$ & 7 \\
\hline Bittker et al., 2018 [16] & Case-control & 1515 & USA & $3-12$ years & Postnatal antibiotic use was associated with an increased ASD risk. & 6 \\
\hline Grossi et al., 2016 [23] & Case-control & 113 & Italy & $5-16$ years & $\begin{array}{l}\text { Regarding potential risk factors, the frequency of early antibiotic } \\
\text { use was higher in the autism group than in the typical group. }\end{array}$ & 7 \\
\hline Guisso et al., 2018 [24] & Case-control & 314 & Lebanon & $2-18$ years & $\begin{array}{c}\text { In the multivariable analysis, antibiotics were negatively } \\
\text { associated with ASD. }\end{array}$ & 7 \\
\hline Hamad et al., 2018 [25] & Cohort & 214,834 & Canada & $2-8$ years & Children who received antibiotics had a reduced ASD risk. & 7 \\
\hline House et al., 2016 [26] & Cross-sectional & 949,821 & USA & $0-17$ years & $\begin{array}{l}\text { The rate of antibiotic use among children diagnosed with ASD was } \\
\text { more than 2-fold that of the general population. }\end{array}$ & 8 \\
\hline Isaksson et al., 2017 [27] & Case-control & 415 & Sweden & $4-9$ years & $\begin{array}{c}\text { An environmental risk index based on the use of antibiotics during } \\
\text { pregnancy and/or the breastfeeding period was associated } \\
\text { with ASD. }\end{array}$ & 7 \\
\hline Vargason et al., 2019 [28] & Cohort & 281,623 & USA & $0-5$ years & $\begin{array}{l}\text { Greater numbers of oral antibiotic fills during the first } 3 \text { years of } \\
\text { enrollment were found to significantly increase the hazard rate of } \\
\text { having a later GI-related diagnosis in both children with and } \\
\text { without ASD. }\end{array}$ & 7 \\
\hline
\end{tabular}

${ }^{*}$ Quality was assessed using the Newcastle-Ottawa Scale. 


\subsection{Meta-Analysis Result Relating the ASD Risk in Antibiotic Exposure}

To investigate the association between ASD and antibiotic exposure, the ASD risk was analyzed based on the antibiotic exposure and control group. As shown in Figure 2A, meta-analysis results indicated that early antibiotic exposure, including pre- and postnatal, significantly increased the ASD risk in children (OR $=1.229,95 \% \mathrm{CI}$ : 1.094-1.381, $p=0.001$ ) with moderate heterogeneity $\left(I^{2}=61.71\right)$. As shown in Figure 2B, the results of subgroup analyses showed that prenatal antibiotic exposure significantly increased the ASD risk (OR $=1.488,95 \% \mathrm{CI}: 1.023-2.165, p=0$. 038) with moderate heterogeneity $\left(I^{2}=54.97\right)$. Furthermore, as shown in Figure $2 \mathrm{C}$, postnatal antibiotic exposure significantly increased the ASD risk in children (OR $=1.159,95 \%$ CI: $1.040-1.293, p=0.008$, $I^{2}=50.62$ ). Moderate heterogeneity was identified across all studies; therefore, as shown in Figure 2 , a random-effects model was performed. The funnel plots and Egger's test $(p=0.03)$ showed significant results in seven of the included studies; however, in subgroup analyses, the results of the Egger' tests (Figure 2B; $p=0.50$, Figure 2C; $p=0.13$ ) were not significant, indicating no publication bias.

(A) Total

\begin{tabular}{lccccc} 
Study name & \multicolumn{5}{c}{ Statistics for each study } \\
\cline { 2 - 6 } & $\begin{array}{c}\text { Odds } \\
\text { ratio }\end{array}$ & $\begin{array}{c}\text { Lower } \\
\text { limit }\end{array}$ & $\begin{array}{c}\text { Upper } \\
\text { limit }\end{array}$ & Z-Value & p-Value \\
Atladottir et al., 2012 & 1.293 & 1.137 & 1.470 & 3.918 & 0.000 \\
Bittker et al., 2018 & 1.215 & 0.963 & 1.532 & 1.644 & 0.100 \\
Grossi et al., 2016 & 2.727 & 1.013 & 7.342 & 1.986 & 0.047 \\
Guisso et al., 2018 & 2.832 & 1.379 & 5.819 & 2.834 & 0.005 \\
Hamad et al., 2018 & 1.083 & 1.007 & 1.164 & 2.137 & 0.033 \\
Isaksson et al., 2017 & 1.270 & 0.744 & 2.169 & 0.877 & 0.380 \\
Vargason et al., 2018 & 1.203 & 1.081 & 1.339 & 3.396 & 0.001 \\
& 1.229 & 1.094 & 1.381 & 3.469 & 0.001
\end{tabular}

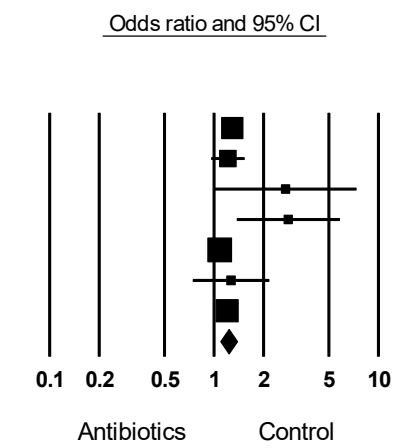

(B) Prenatal

Study name

Atladottir et al., 2012

Guisso et al., 2018

Isaksson et al., 2017

\begin{tabular}{|c|c|c|c|c|}
\hline \multirow[b]{2}{*}{$\begin{array}{c}\text { Odds } \\
\text { ratio }\end{array}$} & \multicolumn{4}{|c|}{ each study } \\
\hline & $\begin{array}{c}\text { Lower } \\
\text { limit }\end{array}$ & $\begin{array}{c}\text { Upper } \\
\text { limit }\end{array}$ & Z-Value & $\mathrm{p}$-Value \\
\hline 1.293 & 1.137 & 1.470 & 3.918 & 0.000 \\
\hline 2.832 & 1.379 & 5.819 & 2.834 & 0.005 \\
\hline 1.270 & 0.744 & 2.169 & 0.877 & 0.380 \\
\hline 1.488 & 1.023 & 2.165 & 2.077 & 0.038 \\
\hline
\end{tabular}

$\begin{array}{lllll}1.488 & 1.023 & 2.165 & 2.077 & 0.038\end{array}$
Odds ratio and $95 \% \mathrm{Cl}$

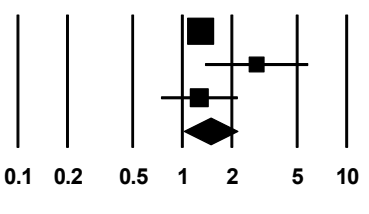

Antibiotics Control

(C) Postnatal

Study name

Bittker et al., 2018
Grossi et al., 2016
Hamad et al., 2018
Vargason et al., 2018

\begin{tabular}{|c|c|c|c|c|}
\hline \multirow[b]{2}{*}{$\begin{array}{l}\text { Odds } \\
\text { ratio }\end{array}$} & \multicolumn{4}{|c|}{ Statistics for each study } \\
\hline & $\begin{array}{c}\text { Lower } \\
\text { limit }\end{array}$ & $\begin{array}{c}\text { Upper } \\
\text { limit }\end{array}$ & Z-Value & p-Valu \\
\hline 215 & 0.963 & 1.532 & 1.644 & $0.1 c$ \\
\hline 2.727 & 1.013 & 7 & 986 & 0.0 \\
\hline & & & & 0.0 \\
\hline & & & & 0.0 \\
\hline & 1.040 & 1.293 & 2.657 & 0.0 \\
\hline
\end{tabular}

Odds ratio and $95 \% \mathrm{Cl}$

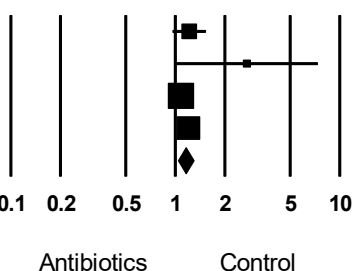

Figure 2. Meta-analysis of the odds ratio estimate of ASD risk according to antibiotic exposure in children. Effects sizes are measured as odds ratio in the antibiotic exposed group compared to that in the control group. (A) Forest plot of the ASD risk in early (pre- and postnatal) antibiotic exposure. Heterogeneity, $\mathrm{Q}=15.669, p=0.016, I^{2}=61.709$ (B) Forest plot of the ASD risk in prenatal antibiotic 
exposure. Heterogeneity, $\mathrm{Q}=4.441, p=0.109, I^{2}=54.966$ (C) Forest plot of the ASD risk in postnatal antibiotic exposure. Heterogeneity, $Q=6.075, p=0.108, I^{2}=50.619$.

\subsection{Meta-Analysis Results Related to Antibiotic Exposure in ASD}

To assess the association between ASD and antibiotic exposure in children, we analyzed differences in antibiotic exposure between the ASD and control groups. Meta-analysis results showed significantly increased early antibiotic exposure, including pre- and postnatal, in children with ASD (SMD $=0.406$, 95\% CI: $0.045-0.768, p=0.028$ ) (Figure 3A). Further, there was obvious heterogeneity in the included studies $\left(I^{2}=99.26\right)$; therefore, we applied a random-effects model to the analysis. The funnel plots and Egger's test did not give significant results $(p=0.67)$, indicating no publication bias. In the subgroup analyses, prenatal antibiotic exposure was significantly increased in children with ASD (SMD $=0.219$, 95\% CI: 0.012-0.426, $p=0.038)$ with moderate heterogeneity $\left(I^{2}=54.97\right)$ (Figure 2B). However, as shown in Figure 3C, there was no significant difference in the postnatal antibiotic exposure between children with ASD and controls (SMD $=0.479,95 \%$ CI: -0.029 to $0.986, p=0.064, I^{2}=99.53$ ). As shown in Figure 3 , there was significant heterogeneity across all studies; therefore, a random-effects model was performed. Furthermore, the funnel plots and Egger's test performed for all studies did not show statistical significance (Figure 3A; $p=0.67$. Figure 3B; $p=0.50$, Figure $3 C ; p=0.67$ ), indicating no publication bias.

(A) Total

\begin{tabular}{|c|c|c|c|c|c|c|c|}
\hline \multirow[t]{2}{*}{$\underline{\text { Study name }}$} & \multicolumn{7}{|c|}{ Statistics for each study } \\
\hline & $\begin{array}{l}\text { Std diff } \\
\text { in means }\end{array}$ & $\begin{array}{l}\text { Standard } \\
\text { error }\end{array}$ & Variance & $\begin{array}{c}\text { Lower } \\
\text { limit }\end{array}$ & $\begin{array}{c}\text { Upper } \\
\text { limit }\end{array}$ & Z-Value & $\mathrm{p}$-Value \\
\hline Idams et al., 2007 & 0.727 & 0.404 & 0.163 & -0.065 & 1.518 & 1.799 & 0.072 \\
\hline t al., 2012 & 0.141 & 0.036 & 001 & 0.071 & 0.212 & 918 & 0.000 \\
\hline ll., 2018 & 0.223 & 0.071 & 005 & 0.085 & 0.362 & 155 & 0.002 \\
\hline 2016 & 53 & 279 & 078 & 0.007 & 1.099 & 986 & 0.047 \\
\hline al., 2018 & 574 & 0.203 & 0.041 & 0.177 & 0.971 & .834 & 0.005 \\
\hline Hamad & & & & 0.004 & 0.084 & 137 & 0.033 \\
\hline Hous & & & 001 & 1.242 & 1.377 & 38.029 & 0.000 \\
\hline 2017 & & & .023 & -0.163 & 0.427 & 877 & 0.380 \\
\hline 1., 2018 & & & & & & 396 & 0.001 \\
\hline & 0.406 & 0.185 & 0.034 & 0.045 & 0.768 & 2.202 & 0.028 \\
\hline
\end{tabular}

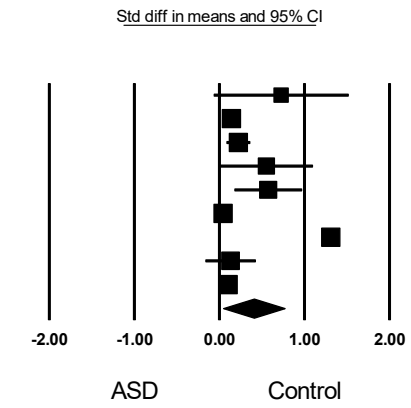

(B) Prenatal

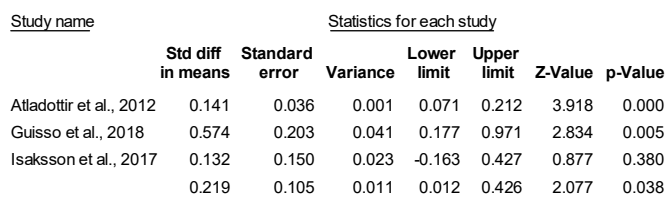

Std diff in means and $95 \% \mathrm{Cl}$

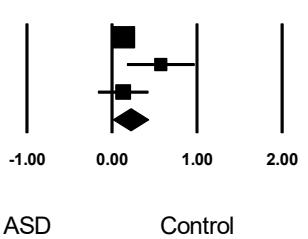

(C) Postnatal

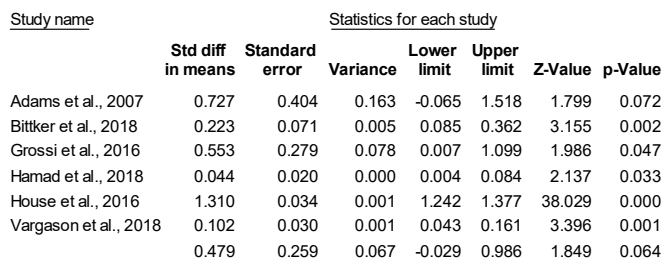

Std diff in means and $95 \% \mathrm{Cl}$

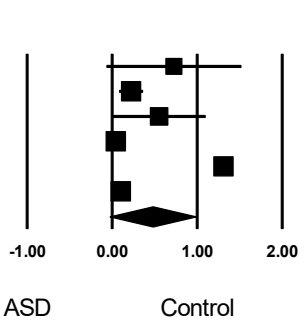

Figure 3. Meta-analysis of early antibiotic exposure in children with ASD. Effects sizes were measured as standardized mean difference in the ASD group compared to that in the control group. (A) Forest 
plot of early (pre- and postnatal) antibiotic exposure in children with ASD. Heterogeneity, Q = 1082.915, $p<0.001, I^{2}=99.261$ (B) Forest plot of prenatal antibiotic exposure in children with ASD. Heterogeneity, $\mathrm{Q}=4.441, p=0.109, I^{2}=54.966(\mathrm{C})$ Forest plot of postnatal antibiotic exposure in children with ASD. Heterogeneity, $\mathrm{Q}=1062.851, p<0.001, I^{2}=99.530$.

\section{Discussion}

This study analyzed the relationship between ASD and early antibiotic use in children using two-sided meta-analyses. Specifically, we analyzed the relationship between ASD and pre- and postnatal antibiotic exposure in children using a systematic method. Our results indicated that preand postnatal antibiotic use increased the ASD risk. This is consistent with previous reports that preand postnatal antibiotic use causes ASD in children [10,13,17-19]. In our study, both pre- and postnatal antibiotic use increased the ASD risk (Figure 2); however, only prenatal, but not postnatal, antibiotic use was significantly elevated in children with ASD compared to controls (Figure 3). It is difficult to compare or discuss the risk levels of prenatal and postnatal antibiotic use because studies on the relationship between ASD risk and postnatal antibiotic use did not specify the prenatal antibiotic exposure $[16,24]$. Further, studies on the relationship between ASD onset and prenatal antibiotic use did not specifically mention a follow-up on postnatal antibiotic exposure [12]. However, the results of our bidirectional meta-analysis suggest that prenatal antibiotic exposure is a more potent risk factor for ASD. This is further indicated by a pre-birth cohort study that examined the association between pre- and postnatal smoking exposure and atopic eczema, and reported that only prenatal smoking exposure increased the risk of atopic eczema by 7.11 times compared to postnatal smoking exposure [29]. Moreover, ASD, which is an early complex neurodevelopmental disorder, is known to develop before the age of three [30]. In particular, the fetal period is a crucial period in brain development and exposure to harmful environmental factors during this period can substantially increase the risk of neurodevelopmental disorders [31]. One study reported that prenatal opiate exposure affected brain development [32]. Therefore, prenatal antibiotic exposure is believed to be an important risk factor for ASD onset [33,34]. Indeed, early postnatal antibiotic exposure is known to increase ASD risk. However, in our study, the reduced influence of postnatal antibiotic exposure on increasing ASD risk could be attributed to the age range of our study population (birth to 18 years). Further studies comparing pre- and postnatal antibiotic use with adjustment for various confounders should be conducted to confirm our results.

Although we systematically analyzed the relationship between ASD and early antibiotic exposure, this study has a few limitations. First, although we analyzed various data on antibiotic exposure, including the number and amount of exposure as well as diverse antibiotic mechanisms, we could not analyze according to antibiotic type due to insufficient data. Further, we did not consider the gestational age in prenatal exposure and used a wide age range for postnatal exposure. Second, although we used a random-effects model to address the high heterogeneity and indicated no publication bias, except for the total results relating to ASD in early exposure, we had a limited sample size. Third, postnatal antibiotic exposure remains controversial. Although the test results on publication bias showed low statistical significance, they cannot be considered conclusive on their own given the small sample size and their closeness to statistical significance. There has been ambiguity in distinguishing different periods in previous studies on the effects of pre- and postnatal antibiotic use. Further, small experimental and large investigative studies reported contradicting findings due to the difficulty of adjusting for various confounders, which were described as limitations. Thus, there is a need for large controlled experimental or cohort studies adjusting for potential confounders to clearly determine the impact of postnatal antibiotic exposure on ASD. 


\section{Conclusions}

Notwithstanding these limitations, this study remains significant since it used two-sided meta-analyses to systematically analyze the relationship between ASD and early antibiotic exposure and provides more evidence on the association between ASD risk and prenatal antibiotic exposure. Subsequent studies should further analyze the association of pre- and postnatal antibiotic exposure with ASD to contribute towards lowering the ASD risk and the prevention and management of ASD in children.

Author Contributions: Conceptualization, E.L., J.C. and K.Y.K.; methodology, E.L., J.C. and K.Y.K.; investigation, E.L., J.C., and K.Y.K.; writing - original draft preparation, E.L. and K.Y.K.; writing - review and editing, E.L., J.C., and K.Y.K.; supervision, K.Y.K.; project administration, E.L. and K.Y.K.

Funding: This work was supported by the National Research Foundation of Korea (NRF) grant funded by the Korea government (MSIP: Ministry of Science, ICT \& Future Planning) (2017R1C1B5017938).

Conflicts of Interest: The authors declare no conflict of interest.

\section{References}

1. American Psychiatric Association. Diagnostic and Statistical Manual of Mental Disorders: DSM-5, 5th ed.; Arlington, V.A., Ed.; American Psychiatric Association: Washington, DC, USA, 2013.

2. Baxter, A.J.; Brugha, T.S.; Erskine, H.E.; Scheurer, R.W.; Vos, T.; Scott, J.G. The epidemiology and global burden of autism spectrum disorders. Psychol. Med. 2015, 45, 601-613. [CrossRef] [PubMed]

3. GBD 2016 Disease and Injury Incidence and Prevalence Collaborators. Global, regional, and national incidence, prevalence, and years lived with disability for 328 diseases and injuries for 195 countries, 1990-2016: A systematic analysis for the Global Burden of Disease Study 2016. Lancet 2017, 390, 1211-1259. [CrossRef]

4. Christensen, D.L.; Maenner, M.J.; Bilder, D.; Constantino, J.N.; Daniels, J.; Durkin, M.S.; Fitzgerald, R.T.; Kurzius-Spencer, M.; Pettygrove, S.D.; Robinson, C.; et al. Prevalence and characteristics of autism spectrum disorder among children aged 4 years-Early autism and developmental disabilities monitoring network, seven sites, United States, 2010, 2012, and 2014. MMWR Surveill. Summ. 2019, 68, 1-19. [CrossRef] [PubMed]

5. Taylor, B.; Jick, H.; Maclaughlin, D. Prevalence and incidence rates of autism in the UK: Time trend from 2004-2010 in children aged 8 years. BMJ Open 2013, 3, e003219. [CrossRef]

6. Geschwind, D.H. Genetics of autism spectrum disorders. Trends Cogn. Sci. 2011, 15, 409-416. [CrossRef]

7. Hallmayer, J.; Cleveland, S.; Torres, A.; Phillips, J.; Cohen, B.; Torigoe, T.; Miller, J.; Fedele, A.; Collins, J.; Smith, K.; et al. Genetic heritability and shared environmental factors among twin pairs with autism. Arch. Gen. Psychiatry 2011, 68, 1095-1102. [CrossRef]

8. Bernard, S.; Enayati, A.; Redwood, L.; Roger, H.; Binstock, T. Autism: A novel form of mercury poisoning. Med. Hypotheses 2001, 56, 462-471. [CrossRef]

9. Mahaffey, K.R.; Clickner, R.P.; Bodurow, C.C. Blood organic mercury and dietary mercury intake: National Health and Nutrition Examination Survey, 1999 and 2000. Environ. Health Perspect. 2004, 112, 562-570. [CrossRef]

10. Hamad, A.F.; Alessi-Severini, S.; Mahmud, S.M.; Brownell, M.; Kuo, I.F. Prenatal antibiotics exposure and the risk of autism spectrum disorders: A population-based cohort study. PLoS ONE 2019, 14, e0221921. [CrossRef]

11. Liew, Z.; Ritz, B.; Virk, J.; Olsen, J. Maternal use of acetaminophen during pregnancy and risk of autism spectrum disorders in childhood: A Danish national birth cohort study. Autism Res. 2016, 9, 951-958. [CrossRef]

12. Atladottir, H.O.; Henriksen, T.B.; Schendel, D.E.; Parner, E.T. Autism after infection, febrile episodes, and antibiotic use during pregnancy: An exploratory study. Pediatrics 2012, 130, e1447-e1454. [CrossRef] [PubMed]

13. Schulfer, A.F.; Battaglia, T.; Alvarez, Y.; Bijnens, L.; Ruiz, V.E.; Ho, M.; Robinson, S.; Ward, T.; Cox, L.M.; Rogers, A.B.; et al. Intergenerational transfer of antibiotic-perturbed microbiota enhances colitis in susceptible mice. Nat. Microbiol. 2018, 3, 234-242. [CrossRef] [PubMed] 
14. Schultz, S.T.; Klonoff-Cohen, H.S.; Wingard, D.L.; Akshoomoff, N.A.; Macera, C.A.; Ji, M. Acetaminophen (paracetamol) use, measles-mumps-rubella vaccination, and autistic disorder: The results of a parent survey. Autism 2008, 12, 293-307. [CrossRef] [PubMed]

15. Adams, J.B.; Romdalvik, J.; Ramanujam, V.M.; Legator, M.S. Mercury, lead, and zinc in baby teeth of children with autism versus controls. J. Toxicol. Environ. Health A 2007, 70, 1046-1051. [CrossRef]

16. Bittker, S.S.; Bell, K.R. Acetaminophen, antibiotics, ear infection, breastfeeding, vitamin D drops, and autism: An epidemiological study. Neuropsychiatr. Dis. Treat. 2018, 14, 1399-1414. [CrossRef]

17. Borre, Y.E.; O'Keeffe, G.W.; Clarke, G.; Stanton, C.; Dinan, T.G.; Cryan, J.F. Microbiota and neurodevelopmental windows: Implications for brain disorders. Trends Mol. Med. 2014, 20, 509-518. [CrossRef]

18. Petra, A.I.; Panagiotidou, S.; Hatziagelaki, E.; Stewart, J.M.; Conti, P.; Theoharides, T.C. Gut-microbiota-brain axis and its effect on neuropsychiatric disorders with suspected immune dysregulation. Clin. Ther. 2015, 37, 984-995. [CrossRef]

19. Mezzelani, A.; Landini, M.; Facchiano, F.; Raggi, M.E.; Villa, L.; Molteni, M.; De Santis, B.; Brera, C.; Caroli, A.M.; Milanesi, L.; et al. Environment, dysbiosis, immunity and sex-specific susceptibility: A translational hypothesis for regressive autism pathogenesis. Nutr. Neurosci. 2015, 18, 145-161. [CrossRef]

20. Moher, D.; Liberati, A.; Tetzlaff, J.; Altman, D.G.; Group, P. Preferred reporting items for systematic reviews and meta-analyses: The PRISMA statement. J. Clin. Epidemiol. 2009, 62, 1006-1012. [CrossRef]

21. Bae, J.M. A suggestion for quality assessment in systematic reviews of observational studies in nutritional epidemiology. Epidemiol. Health 2016, 38, e2016014. [CrossRef]

22. Well, G.A.; Shea, B.; O'Connell, D.; Peterson, J.; Welch, V.; Losos, M.; Tugwell, P. The Newcastle-Ottawa Scale (NOS) for Assessing the Quality of Nonrandomised Studies in Meta-Analyses. Available online: http://www.ohri.ca/programs/clinical_epidemiology/oxford.asp (accessed on 26 June 2019).

23. Grossi, E.; Veggo, F.; Narzisi, A.; Compare, A.; Muratori, F. Pregnancy risk factors in autism: A pilot study with artificial neural networks. Pediatric Res. 2016, 79, 339-347. [CrossRef] [PubMed]

24. Guisso, D.R.; Saadeh, F.S.; Saab, D.; El Deek, J.; Chamseddine, S.; Abou-El-Hassan, H.; Majari, G.; Boustany, R.M. Association of autism with maternal infections, perinatal and other risk factors: A case-control study. J. Autism Dev. Disord. 2018, 48, 2010-2021. [CrossRef] [PubMed]

25. Hamad, A.F.; Alessi-Severini, S.; Mahmud, S.M.; Brownell, M.; Kuo, I.F. Early childhood antibiotics use and autism spectrum disorders: A population-based cohort study. Int. J. Epidemiol. 2018, 47, 1497-1506. [CrossRef] [PubMed]

26. House, S.A.; Goodman, D.C.; Weinstein, S.J.; Chang, C.H.; Wasserman, J.R.; Morden, N.E. Prescription use among children with autism spectrum disorders in northern New England: Intensity and small area variation. J. Pediatrics 2016, 169, 277-283.e2. [CrossRef] [PubMed]

27. Isaksson, J.; Pettersson, E.; Kostrzewa, E.; Diaz Heijtz, R.; Bolte, S. Brief report: Association between autism spectrum disorder, gastrointestinal problems and perinatal risk factors within sibling pairs. J. Autism Dev. Disord. 2017, 47, 2621-2627. [CrossRef]

28. Vargason, T.; McGuinness, D.L.; Hahn, J. Gastrointestinal symptoms and oral antibiotic use in children with autism spectrum disorder: Retrospective analysis of a privately insured U.S. population. J. Autism Dev. Disord. 2019, 49, 647-659. [CrossRef]

29. Tanaka, K.; Miyake, Y.; Furukawa, S.; Arakawa, M. Pre-and postnatal smoking exposure and risk of atopic eczema in young Japanese children: A prospective prebirth cohort study. Nicotine Tob. Res. 2017, 19, 804-809. [CrossRef]

30. Xiao, Z.; Qiu, T.; Ke, X.; Xiao, X.; Xiao, T.; Liang, F.; Zou, B.; Huang, H.; Fang, H.; Chu, K.; et al. Autism spectrum disorder as early neurodevelopmental disorder: Evidence from the brain imaging abnormalities in 2-3 years old toddlers. J. Autism Dev. Disord. 2014, 44, 1633-1640. [CrossRef]

31. Bellinger, D.C. Prenatal exposures to environmental chemicals and children's neurodevelopment: An update. Saf. Health Work 2013, 4, 1-11. [CrossRef]

32. Walhovd, K.B.; Moe, V.; Slinning, K.; Siqveland, T.; Fjell, A.M.; Bjornebekk, A.; Smith, L. Effects of prenatal opiate exposure on brain development-A call for attention. Nat. Rev. Neurosci. 2009, 10, 390. [CrossRef] 
33. Fang, S.Y.; Wang, S.; Huang, N.; Yeh, H.H.; Chen, C.Y. Prenatal infection and autism spectrum disorders in childhood: A population-based case-control study in Taiwan. Paediatr. Perinat. Epidemiol. 2015, 29, 307-316. [CrossRef] [PubMed]

34. Zerbo, O.; Qian, Y.; Yoshida, C.; Grether, J.K.; Van de Water, J.; Croen, L.A. Maternal infection during pregnancy and autism spectrum disorders. J. Autism Dev. Disord. 2015, 45, 4015-4025. [CrossRef] [PubMed]

(C) 2019 by the authors. Licensee MDPI, Basel, Switzerland. This article is an open access article distributed under the terms and conditions of the Creative Commons Attribution (CC BY) license (http://creativecommons.org/licenses/by/4.0/). 